\title{
Diffusion-weighted MRI at 3T in Endometrial Cancer: Correlation of Apparent Diffusion Coefficient with Histopathological Prognostic Parameters
}

\author{
Mesut Ozturk ${ }^{1}$, Cihan Kalkan², Murat Danaci ${ }^{2}$ and Mehmet Kefeli ${ }^{3}$ \\ ${ }^{1}$ Department of Radiology, Samsun Gazi State Hospital, Samsun, Turkey \\ ${ }^{2}$ Department of Radiology, Faculty of Medicine, Ondokuz Mayis University, Samsun, Turkey \\ ${ }^{3}$ Department of Pathology, Faculty of Medicine, Ondokuz Mayis University, Samsun, Turkey
}

\begin{abstract}
Objective: To evaluate the value of apparent diffusion coefficient (ADC) for the differentiation of histological subtypes in endometrial cancer, and to assess if ADC values correlate with histopathological parameters.

Study Design: Descriptive study.

Place and Duration of Study: Department of Radiology, Faculty of Medicine, Ondokuz Mayis University between January 2016 and December 2019.

Methodology: Eighty-three patients (mean age: $60.28 \pm 9.07$ ) with endometrial cancer underwent diffusion-weighted imaging ( $D W I)$ at $3 T$ before surgery. The mean $A D C\left(A D C_{\text {mean }}\right)$ and minimum $A D C\left(A D C_{\text {min }}\right)$ values of the tumours were assessed to predict histological subtype of endometrial cancer, grade of tumour, presence of myometrial invasion, lower uterine segment involvement, cervical involvement, lymphovascular invasion, and lymph node metastasis.

Results: Sixty patients (72.3\%) were diagnosed with endometrioid carcinoma, and 23 patients (27.7\%) were diagnosed with non-endometrioid carcinoma. The median $A D C_{\text {mean }} / A D C_{\text {min }}$ of endometrioid and non-endometrioid tumours were $0.72 / 0.58 \times 10^{-3} \mathrm{~mm}^{2} / \mathrm{s}$ and $0.82 / 0.63 \times 10^{-3} \mathrm{~mm}^{2} / \mathrm{s}$, respectively. $A D C_{\text {mean }}$ and $A D C_{\min }$ were significantly different between endometrioid and non-endometrioid tumours $(p=0.016$ and $p=0.048)$. For the endometrioid carcinomas, $A D C_{\text {mean }}$ and $A D C_{\text {min }}$ were significantly different between low-grade (G1 and G2) and high-grade (G3) tumours $\left(A D C_{\text {mean }} / A D C_{\text {min }}=\right.$ $0.75 / 0.65$ vs. $0.59 / 0.49 \times 10^{-3} \mathrm{~mm}^{2} / \mathrm{s}, \mathrm{p}=0.010$ and $\mathrm{p}=0.013$ ). Myometrial invasion, lymphovascular invasion, cervical involvement, lower uterine involvement, serosal involvement and lymph node metastasis were not significantly associated with $A D C$ values.

Conclusion: ADC measurements were useful for differentiating endometrioid and non-endometrioid carcinomas. High-grade endometrioid carcinomas had significantly lower ADC values compared to low-grade ones.
\end{abstract}

Key Words: Endometrial cancer, Diffusion-weighted MRI, Apparent diffusion coefficient, Prognostic factors, Histological grade.

How to cite this article: Ozturk M, Kalkan C, Danaci M, Kefeli M. Diffusion-weighted MRI at 3T in Endometrial Cancer: Correlation of Apparent Diffusion Coefficient with Histopathological Prognostic Parameters. J Coll Physicians Surg Pak 2021; 31(12):1399-1405.

\section{INTRODUCTION}

Endometrial cancer is one of the most common gynaecological malignancies in women. ${ }^{1}$ Accurate staging of the tumour at the time of diagnosis is vital for both the appropriate treatment planning and the accurate prediction of the disease prognosis. ${ }^{2}$

Correspondence to: Dr. Mesut Ozturk, Department of Radiology, Samsun Gazi State Hospital, Samsun, Turkey E-mail:dr.mesutozturk@gmail.com

Received: July 19, 2021; Revised: September 17, 2021;

Accepted: October 29, 2021

DOI: https://doi.org/10.29271/jcpsp.2021.12.1399
The International Federation of Gynecological and Obstetrics (FIGO) staging is the most commonly used staging system in the staging of endometrial carcinoma. According tothis classification, the myometrial invasion depth, presence of cervical invasion, lymphatic system involvement, and histological grade are important histological features..$^{3.5}$ Although the FIGO staging system is a surgical staging system, it is important to evaluate those patients non-invasively before surgery to plan accurate surgical procedures.

Magnetic resonance imaging (MRI) is the preferred radiological imaging method for the pre-treatment evaluation of endometrial cancer cases. Conventional MRI provides valuable information about lesion size and extension, but the major limitation of $\mathrm{MRI}$ is that it cannot accurately predict the presence of lymph node metastasis and lymphovascular invasion. ${ }^{6,7}$ Besides the 
conventional sequences that provide anatomical information, sequences that provide functional information are also used in MRI.

Diffusion-weighted imaging (DWI) is a functional MRI sequence measuring the free diffusion movement of water molecules in biological tissues. ${ }^{5} \mathrm{DWl}$ imaging has gained importance in the management of gynaecological malignancies in recent years, and many DWI-related studies have been conducted. ${ }^{8-15}$ Theoretically, as in other organs, malignant endometrial lesions are expected to have lower apparent diffusion coefficient (ADC) values than benign lesions. ${ }^{5,16}$ In addition, ADC measurement in malignant tumours is thought to be associated with histological parameters, and several studies measuring ADC in endometrial cancers have been published. ${ }^{5,8,10-12,15,17-22}$ However, some studies have reported that ADC values are associated with some prognostic histological factors. ${ }^{10,19,20}$ Some other studies have also reported that there is no relationship between prognostic histological features and ADC measurements. ${ }^{5,8,11}$ Thus, more studies are needed on this issue.

The aim of this study was to investigate the relationship between the ADC values obtained from DWI and the important prognostic histological parameters of endometrial carcinoma.

\section{METHODOLOGY}

The current study was approved by the Institutional Ethics Committee and the requirement for informed consent was waived, as the data was restrospectively collected. The standards for reporting of diagnostic accuracy studies (STARD) was used. $^{23}$

The hospital database was retrospectively reviewed to identify patients who underwent 3TMRI, including DWI, for the pre-operative evaluation of endometrial cancer at Department of Radiology, Faculty of Medicine, Ondokuz Mayis University between January 2016 and December 2019. Ninety-six patients were found. Six patients were excluded because their tumours were extremely small or because these tumours could not be clearly demonstrated on DWI. Furthermore, four patients whose surgical pathology results were not available and three patients because of severe artefacts were also excluded. As a result, 83 patients were enrolled in the study. All patients underwent hysterectomy, and the final diagnoses of the patients were based on the histopathological results.

MRI examinations of the patients were performed with a 3T system (Ingenia, Philips Healthcare, Netherlands). Routine MRI examination of patients referred with the suspicion of endometrial cancer in this centre included the following sequences: axial, coronal and sagittal T2-weighted fast spin-echo sequences (TR/TE: $3514 / 90$, FOV: $240 \times 240$, matrix: $368 \times 302$, slice thickness: $3 \mathrm{~mm})$; axial T1-weighted mDIXON sequence (TR/TE: $2.9 / 0.99$, FOV: $350 \times 318$, matrix: $148 \times 133$, slice thickness: $4 \mathrm{~mm}$ ); axial fat-suppressed, dynamic contrast enhanced T1-weighted 3D radial gradient-recalled echo sequence (volumetric interpolated breath-hold examination [VIBE]) (TR/TE:
3.1/1.09, FOV: $357 \times 277$, matrix: $180 \times 140$, slice thickness: 4 $\mathrm{mm})$. DWI sequences were obtained, using the single-shot spin-echo (EPI) technique with the following parameters: FOV: $375 \times 315$; matrix: $124 \times 106$; NEX: 4; acquisition time: 03:53; and b values: 0,200 and $800 \mathrm{~s} / \mathrm{mm}^{2}$. ADC maps were automatically generated on the scanner console on a pixel-by-pixel basis from DWI images.

All acquired images were sent to a workstation, equipped with Osirix DICOM viewer software version 3.8.1 (Osirix, Pixmeo, Switzerland). DWI interpretation was performed by a radiologist (MO) in consensus with a senior radiology resident (CK) to establish the regions of interest (ROIs) and to measure the tumour size (Figures 1 and 2). The reviewers were aware of the endometrialcarcinoma diagnosis, but were blinded to the histopathological features of the cases. The ROIs were manually drawn with a free-hand technique on the ADC slice depicting the largest tumour. Mean ADC (ADCmean) and minimum ADC (ADCmin) of the lesions were recorded for the statistical analysis.

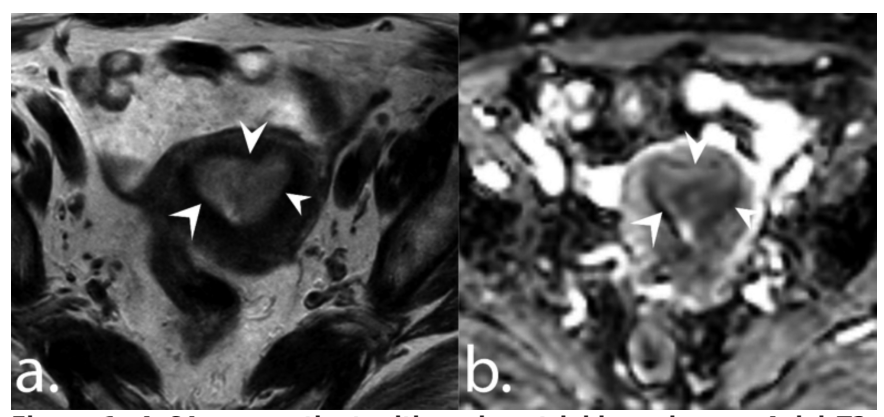

Figure 1: A 64-year patient with endometrioid carcinoma. Axial T2weighted image (a) and ADC map (b) show a tumour in the endometrial cavity (arrowheads). ADC $C_{\text {mean }}$ and $A D C_{\text {min }}$ values of the tumor were 0.77 and $0.67 \times 10^{-3} \mathrm{~mm}^{2} / \mathrm{s}$, respectively.

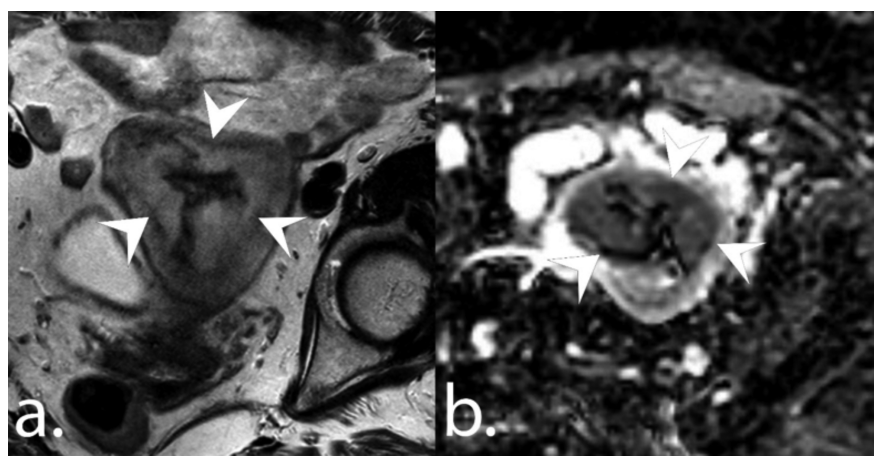

Figure 2: A 72-year patient with non-endometrioid carcinoma. Axial T2weighted image (a) and ADC map (b) show a tumour in the endometrial cavity (arrowheads). The $A D C_{\text {mean }}$ and $A D C_{\text {min }}$ values of the tumour were 0.84 and $0.63 \times 10^{-3} \mathrm{~mm}^{2} / \mathrm{s}$, respectively.

The senior radiology resident performed the histopathological data collection four weeks after finishing the image interpretation. Histopathological data were based on the surgical results of the patients. The pathology results of the patients were reviewed from the hospital database and information about the histological grade, depth of myometrial invasion, lower uterine segment involvement, cervical involvement, serosal involvement, presence of lymphovascular invasion and presence of metastatic lymph nodes were collected. 
Table I: Demographic data of the study population.

\begin{tabular}{|c|c|c|c|c|}
\hline Variable & $\begin{array}{l}\text { Whole population } \\
(n=83)\end{array}$ & $\begin{array}{l}\text { Endometrioid cancer } \\
(n=60)\end{array}$ & $\begin{array}{l}\text { Non-endometrioid cancer } \\
(n=23)\end{array}$ & $\mathbf{p}$ \\
\hline Age & $60.28 \pm 9.07$ & $59.77 \pm 9.58$ & $61.61 \pm 7.61$ & 0.411 \\
\hline Lesion size & $33.05 \pm 16.47$ & $30 \pm 12.94$ & $41 \pm 21.69$ & 0.006 \\
\hline \multicolumn{4}{|l|}{ Grade } & $<0.001$ \\
\hline Grade 1 & $17(20.5 \%)$ & $16(26.7 \%)$ & $1(4.3 \%)$ & \\
\hline Grade 2 & $37(44.6 \%)$ & $33(89.2 \%)$ & $4(17.4 \%)$ & \\
\hline Grade 3 & $29(34.9 \%)$ & $11(18.3 \%)$ & $18(78.3 \%)$ & \\
\hline \multicolumn{4}{|l|}{ Serosal involvement } & 0.184 \\
\hline Present & $3(3.6 \%)$ & $1(1.7 \%)$ & $2(8.7 \%)$ & \\
\hline Absent & $80(96.4 \%)$ & $59(98.3 \%)$ & $21(91.3 \%)$ & \\
\hline \multicolumn{4}{|l|}{ Lower uterine segment involvement } & 0.336 \\
\hline Present & $13(15.7 \%)$ & $8(13.3 \%)$ & $5(21.7 \%)$ & \\
\hline Absent & $70(84.3 \%)$ & $52(86.7 \%)$ & $18(78.3 \%)$ & \\
\hline \multicolumn{4}{|l|}{ Servical involvement } & 0.083 \\
\hline Present & $12(14.5 \%)$ & $6(10 \%)$ & $6(26.1 \%)$ & \\
\hline Absent & $71(85.5 \%)$ & $54(90 \%)$ & $17(73.9 \%)$ & \\
\hline \multicolumn{4}{|l|}{ Lymphovascular invasion } & 0.013 \\
\hline Present & $36(43.4 \%)$ & $21(35.0 \%)$ & $15(65.2 \%)$ & \\
\hline Absent & $47(56.6 \%)$ & $39(65.0 \%)$ & $8(34.8 \%)$ & \\
\hline \multicolumn{4}{|l|}{ Myometrial invasion } & 0.990 \\
\hline$<50 \%$ & $47(56.6 \%)$ & $34(56.7 \%)$ & $13(56.5 \%)$ & \\
\hline$>50 \%$ & $36(43.4 \%)$ & $26(43.3 \%)$ & $10(43.5 \%)$ & \\
\hline \multicolumn{4}{|l|}{ Lymph node metastasis } & 0.001 \\
\hline Present & $13(15.7 \%)$ & $4(6.7 \%)$ & $9(39.1 \%)$ & \\
\hline Absent & $70(84.3 \%)$ & $56(93.3 \%)$ & $14(60.9 \%)$ & \\
\hline
\end{tabular}

Table II: Comparison of the ADC values in the whole population.

\begin{tabular}{|c|c|c|c|c|}
\hline Variable & $\mathrm{ADC}_{\text {mean }}$ & p-value & $\mathbf{A D C}_{\min }$ & p-value \\
\hline \multicolumn{2}{|l|}{ Histological subtype } & 0.016 & & 0.048 \\
\hline Endometrioid & $0.72(0.48-1.19)$ & & $0.58(0.31-0.82)$ & \\
\hline Non-endometrioid & $0.82(0.55-1.37)$ & & $0.63(0.37-1.31)$ & \\
\hline \multicolumn{2}{|l|}{ Grade } & 0.557 & & 0.483 \\
\hline High & $0.73(0.48-1.37)$ & & $0.57(0.33-1.31)$ & \\
\hline Low & $0.75(0.49-1.19)$ & & $0.60(0.31-0.82)$ & \\
\hline \multicolumn{2}{|l|}{ Serosal involvement } & 0.522 & & 0.240 \\
\hline Present & $0.82(0.72-0.86)$ & & $0.66(0.64-0.66)$ & \\
\hline Absent & $0.75(0.48-1.37)$ & & $0.59(0.31-1.31)$ & \\
\hline \multicolumn{2}{|c|}{ Lower uterine segment involvement } & 0.155 & & 0.042 \\
\hline Present & $0.82(0.55-1.31)$ & & $0.66(0.49-1.09)$ & \\
\hline Absent & $0.75(0.48-1.37)$ & & $0.58(0.31-1.31)$ & \\
\hline \multicolumn{2}{|l|}{ Cervical involvement } & 0.861 & & 0.871 \\
\hline Present & $0.76(0.55-1.31)$ & & $0.59(0.31-1.31)$ & \\
\hline Absent & $0.75(0.48-1.37)$ & & $0.58(0.48-1.09)$ & \\
\hline \multicolumn{2}{|c|}{ Lymphovascular invasion } & 0.713 & & 0.520 \\
\hline Present & $0.77(0.55-1.06)$ & & $0.59(0.40-0.77)$ & \\
\hline Absent & $0.73(0.48-1.37)$ & & $0.59(0.31-1.31)$ & \\
\hline \multicolumn{2}{|c|}{ Myometrial invasion depth } & 0.566 & & 0.241 \\
\hline$<50 \%$ & $0.75(0.48-1.37)$ & & $0.58(0.31-1.31)$ & \\
\hline$>50 \%$ & $0.76(0.55-1.06)$ & & $0.61(0.32-0.77)$ & \\
\hline \multicolumn{2}{|c|}{ Lymph node metastasis } & 0.206 & & 0.034 \\
\hline Present & $0.82(0.65-0.99)$ & & $0.66(0.54-0.77)$ & \\
\hline Absent & $0.75(0.48-1.37)$ & & $0.58(0.31-1.31)$ & \\
\hline
\end{tabular}

Table III: Subgroup analysis in patients with endometriod and non-endometrioid endometrial cancer.

\begin{tabular}{|c|c|c|c|c|c|c|c|c|}
\hline \multirow[b]{2}{*}{ Variable } & \multicolumn{4}{|c|}{ Endometrioid endometrial cancer } & \multicolumn{4}{|c|}{ Non-endometrioid endometrial cancer } \\
\hline & $\mathrm{ADC}_{\text {mean }}$ & p-value & $\mathbf{A D C}_{\min }$ & p-value & $\mathrm{ADC}_{\text {mean }}$ & p-value & $\mathbf{A D C}_{\min }$ & p-value \\
\hline Grade & & 0.010 & & 0.013 & & 0.766 & & 0.881 \\
\hline High & $0.65(0.48-0.85)$ & & $0.49(0.33-0.66)$ & & $0.83(0.55-1.37)$ & & $0.64(0.37-1.31)$ & \\
\hline Low & $0.75(0.49-1.19)$ & & $0.59(0.31-0.82)$ & & $0.78(0.75-1.01)$ & & $0.63(0.53-0.79)$ & \\
\hline Serosal involvement & & NA & & NA & & 0.827 & & 0.663 \\
\hline Present & & & & & $0.84(0.82-0.86)$ & & $0.65(0.64-0.66)$ & \\
\hline Absent & & & & & $0.82(0.55-1.37)$ & & $0.63(0.37-1.31)$ & \\
\hline $\begin{array}{l}\text { Lower uterine segment } \\
\text { involvement }\end{array}$ & & 0.617 & & 0.203 & & 0.263 & & 0.136 \\
\hline Present & $0.74(0.55-0.96)$ & & $0.62(0.49-0.76)$ & & $0.86(0.82-1.31)$ & & $0.70(0.58-1.09)$ & \\
\hline Absent & $0.72(0.48-1.19)$ & & $0.56(0.31-0.82)$ & & $0.80(0.55-1.37)$ & & $0.61(0.37-1.31)$ & \\
\hline
\end{tabular}




\begin{tabular}{|c|c|c|c|c|c|c|c|c|}
\hline \multicolumn{2}{|c|}{ Cervical involvement } & \multirow[t]{2}{*}{0.247} & \multirow{2}{*}{$0.54(0.48-0.66)$} & \multirow[t]{2}{*}{0.467} & \multirow[b]{2}{*}{$0.84(0.74-1.31)$} & \multirow[t]{2}{*}{0.624} & \multirow{2}{*}{$0.63(0.55-1.09)$} & \multirow[t]{2}{*}{0.726} \\
\hline Present & $0.71(0.55-0.77)$ & & & & & & & \\
\hline Absent & $0.73(0.48-1.19)$ & & $0.59(0.31-0.82)$ & & $0.82(0.55-1.37)$ & & $0.63(0.37-1.31)$ & \\
\hline \multicolumn{2}{|c|}{ Lymphovascular invasion } & 0.988 & & 0.733 & & 0.259 & & 0.606 \\
\hline Present & $0.74(0.55-1.06)$ & & $0.57(0.40-0.77)$ & & $0.82(0.62-0.96)$ & & $0.63(0.41-0.77)$ & \\
\hline Absent & $0.72(0.48-1.19)$ & & $0.58(0.31-0.82)$ & & $0.91(0.55-1.37)$ & & $0.67(0.37-1.31)$ & \\
\hline \multicolumn{2}{|c|}{ Myometrial invasion depth } & 0.273 & & 0.233 & & 0.385 & & 0.852 \\
\hline$<50 \%$ & $0.72(0.48-1.19)$ & & $0.55(0.31-0.82)$ & & $0.85(0.55-1.37)$ & & $0.64(0.37-1.31)$ & \\
\hline$>50 \%$ & $0.74(0.55-1.06)$ & & $0.59(0.32-0.76)$ & & $0.80(0.65-0.96)$ & & $0.63(0.54-0.77)$ & \\
\hline \multicolumn{2}{|c|}{ Lymph node metastasis } & 0.286 & & 0.058 & & 0.469 & & 0.850 \\
\hline Present & $0.77(0.72-0.99)$ & & $0.66(0.61-0.77)$ & & $0.82(0.65-0.89)$ & & $0.64(0.54-0.72)$ & \\
\hline Absent & $0.72(0.48-1.19)$ & & $0.56(0.31-0.82)$ & & $0.85(0.55-1.37)$ & & $0.63(0.37-1.31)$ & \\
\hline
\end{tabular}

Statistical analysis was performed with the Statistical Package for the Social Sciences version 22.0 (SPSS Inc., Chicago, IL, USA) for Windows. Data were presented as mean and standard deviation (SD) or median and range for continuous variables and as frequencies for categorical variables. Shapiro-Wilk test was used to assess normal distribution of the continuous data. Student t-test or Mann-Whitney $\mathrm{U}$-test was used to compare the continuous variables. Chisquare test was used to compare the categorical variables. Receiver operating characteristics (ROC) curve analysis was performed to evaluate the diagnostic performances of $A D C$ values in differentiating high-grade (G3) and low-grade (G1 $+\mathrm{G} 2$ ) endometrioid carcinomas. Optimal cut-off values were calculated by maximising the Youden index. Spearman correlation was used to evaluate the correlation between ADC values and the histological grade. The degree of correlation was classified as follows: $0 \leq \rho<2$, no relationship; $2 \leq \rho$ $<4$, weak correlation; $4 \leq \rho<6$, moderate correlation; $6 \leq \rho$ $<8$, strong correlation; $8 \leq \mathrm{r}$, very strong correlation. For all assessments, a $p$ value less than 0.05 was indicative of statistical significance.

\section{RESULTS}

A summary of the clinical data of the study population is presented in Table I. The mean age of the study population was $60.28 \pm 9.07$ (range: $34-82$ ) years. There were 60 endometrioid (72.3\%) and 23 non-endometrioid carcinomas (27.7\%). Non-endometrioid histology included 10 serous carcinoma, five carcinosarcoma, four mucinous carcinoma, and four undifferentiated high-grade tumours. The mean age of the patients with endometrioid carcinomas $(59.77 \pm 9.58)$ was not significantly different from that of the patients with non-endometrioid carcinomas (61.61 $\pm 7.61, p=0.411)$. Mean lesion size was $33.05 \pm 16.47 \mathrm{~mm}$. Mean size of the endometrioid carcinomas ( $30 \pm 12.94 \mathrm{~mm}$ ) was significantly smaller than that of the non-endometrioid carcinomas (41 \pm $21.69 \mathrm{~mm}, \mathrm{p}=0.006$ ).

There were 17 grade 1 (G1), 37 grade 2 (G2) and 29 grade 3 (G3) tumours. Tumour grade was significantly different between endometrioid and non-endometrioid tumours ( $p<$ 0.001). Serosal involvement, lower uterine segment involvement, cervical involvement, and myometrial invasion depth were not associated with the histological subtype $(p=$ $0.184, p=0.336, p=0.083$ and $p=0.990$, respectively).
Lymphovascular invasion was more common in non-endometrioid carcinomas $(p=0.013)$. Lymph node metastasis was also more common in non-endometrioid carcinomas ( $p$ $=0.001)$.

Comparison of the ADC values with the histopathological parameters in the whole study population is shown in Table II. Median $A D C_{\text {mean }}$ values of endometrioid carcinomas [ 0.72 $(0.48-1.19)]$ was significantly smaller than that of the nonendometrioid carcinomas [0.82 (0.55 - 1.37), $p=0.016$ ]. Median $\mathrm{ADC}_{\min }$ of endometrioid carcinomas [0.58 (0.31 $0.82)]$ was significantly smaller than that of the non-endometrioid carcinomas [0.63 (0.37 - 1.31), $p=0.048$ ]. There was no correlation between the ADC measurements and the tumour grade $(\rho=-0.068, p=0.540) . A D C_{\text {mean }}$ and $A D C_{\min }$ values of the high-grade (G3) tumours were not significantly different from those of the low-grade (G1 + $\mathrm{G} 2$ ) ones ( $p=0.557$ and $p=0.483$ respectively). Serosal involvement, cervical involvement, lymphovascular invasion and myometrial invasion depth were not associated with the ADC measurements ( $p=0.240-p=0.861$ ). Lower uterine segment involvement and lymph node metastasis were not associated with $A D C_{\text {mean }}$ values $(p=0.155$ and $p=$ 0.206 , respectively). $A D C_{\min }$ values of the cases with lower uterine segment involvement [0.66 (0.49-1.09)] was significantly higher than that of the cases without lower uterine segment involvement $[0.58(0.31-1.31), p=$ 0.042 ]. The $A D C_{\text {min }}$ of the cases with lymph node metastasis [0.66 $(0.54-0.77)]$ was significantly higher than that of the cases without lymph node metastasis [0.58 $(0.31-1.31), p$ $=0.034$.

In the endometrioid carcinoma group, $\mathrm{ADC}_{\text {mean }}$ values of the high-grade tumours $[0.65(0.48-0.85)]$ was significantly lower than that of the low-grade ones [0.75 (0.49-1.19), $p$ $=0.010]$. Similarly, the $A D C_{\min }$ of the high-grade tumours $[0.49(0.33-0.66)]$ was significantly lower than that of the low-grade tumours $[0.59(0.31-0.82), p=0.013]$. An $A D C_{\text {mean }}$ cut-off value of $0.66 \times 10^{-3} \mathrm{~mm}^{2} / \mathrm{s}$ for the diagnosis of a high-grade tumor revealed $63.6 \%$ sensitivity and $83.7 \%$ specificity (AUC: $0.750, \mathrm{Cl}: 0.599-0.900, \mathrm{p}=$ 0.010 ). Selecting a cut-off $A D C_{\min }$ value of $0.54 \times 10^{-3} \mathrm{~mm}^{2} / \mathrm{s}$ revealed sensitivity and specificity values of $81.8 \%$ and $69.4 \%$, respectively (AUC: $0.740, \mathrm{Cl}: 0.604-0.877, \mathrm{p}=$ 
0.013) (Figure 3). There was a weak inverse correlation between the ADC measurements and tumour grade $(\rho=$ $-0.254, p=0.050$ ). Other histopathological features were not associated with the ADC values (Table III).

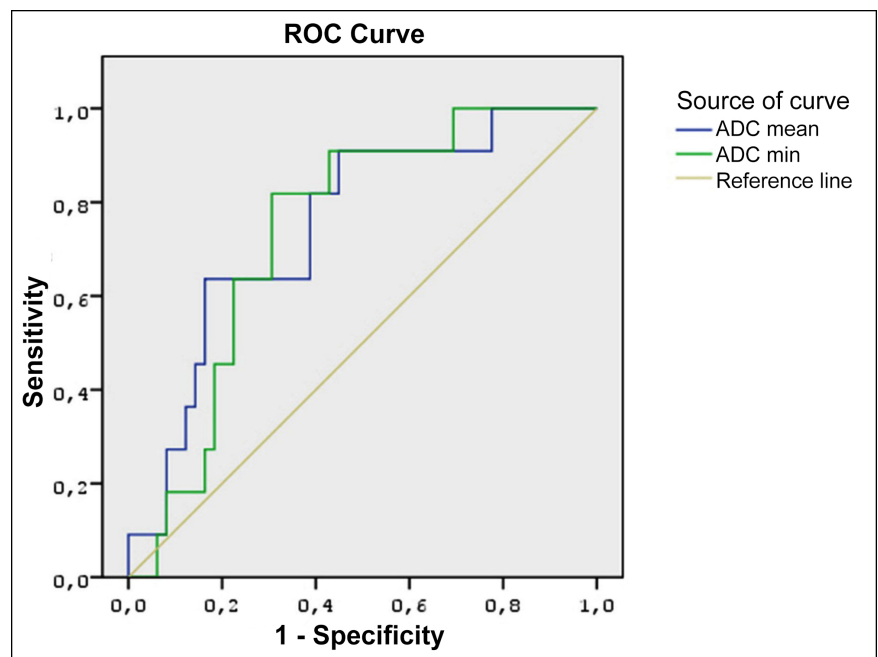

Figure 3: Receiver operating characteristics (ROC) curve analysis for the apparent diffusion coefficient (ADC) values to differentiate high grade and low-grade endometrioid carcinomas.

In the non-endometrioid endometrial tumours, all histopathological features, including tumour grade, were not associated with the $A D C$ measurements. No correlation between the ADC measurements and tumour grade was found $(\rho=$ $-0.091, p=0.678)$.

\section{DISCUSSION}

The aim of the present study was to assess the value of ADC measurements in the differentiation of histological subtypes of endometrial cancer and to assess if the ADC measurements were related to histopathological parameters. ADC measurements were able to differentiate endometrioid and non-endometrioid carcinomas from each other. In the endometrioid carcinoma group, ADC values were differentiated between the low- and high-grade tumours; however, in the non-endometrioid carcinoma group there was no differentiation. Other histopathological parameters were not associated with ADC measurements.

In this study, no correlation was found between the ADC measurements and tumour grade in the whole study population, which was consistent with several previous studies. ${ }^{5,10,20}$ However, high-grade endometrioid carcinomas had significantly lower ADC values than the low-grade ones. In general, malignant tumours have lower ADC values than benign ones, as the reduced extracellular space from increased cellularity limits the Brawnian motion of water molecules. High-grade endometrioid cacinomas have higher cellular density compared to the low-grade ones. Therefore, lower $A D C$ values in high-grade endometrioid carcinomas may be due to the increased mitosis and cellular abundance of those tumours. On the other hand, we found no significant differ- ence between the tumour grade and ADC measurements in non-endometrioid carcinomas. This may be due to various histological subtypes, including mucinous and serous histology in non-endometrioid carcinomas, which may influence the ADC measurements. In a study by Rechichi et al, ${ }^{11}$ no association between ADC measurements and tumour grade were reported. However, they performed statistical analysis only on the whole population and did not perform an analysis on endometrioid carcinomas separately.

Yan et al. evaluated 98 endometrial cancers and measured the mean and minimum ADC of the tumours. ${ }^{21}$ Their paper did not report a significant difference between the ADC values of endometrioid and non-endometrioid carcinomas, which differed from our findings. However, ADC values of endometrioid carcinomas were lower than those of non-endometrioid carcinomas, which was similar to the present findings. They also found a significant difference between the ADC values of low-grade and high-grade endometrioid endometrial cancers, which was quite similar to the present results.

In this study, the authors found no relationship between myometrial invasion depth and the ADC measurements. Some studies in the literature reported a significant association between ADC measurements and myometrial invasion depth. ${ }^{19,20,24}$ However, our findings confirmed other studies by Rechichi et al., ${ }^{11}$ Lin et al., ${ }^{10}$ and Cavusoglu et al., ${ }^{22}$ as they also reported no relationship between ADC and myometrial invasion depth. Rechichi et al. also reported no association between ADC measurements and lymph node metastasis. Their study differed from this study, in that they used a 1.5T MRI scanner. However, using a higher magnetic field strength, our results confirmed their findings.

Regarding lymph node metastasis, $A D C_{\min }$ values in this entire study population was associated with lymph node metastasis. However, the number of cases with lymph node metastasis was quite small. Furthermore, lymph node metastasis did not show a significant relationship with the ADC values in the subgroup analysis of endometrioid and non-endometrioid endometrial cancers. Some previous studies reported no significant correlation between the ADC value and lymph node metastasis. ${ }^{12,13,20}$ More studies with larger populations are needed to investigate the relationship between ADC and lymph node metastasis.

The study had some limitations. First, it was a retrospective one with related limitations. Second, a relatively limited number of patients were included. Third, the ADC measurements were performed by two radiologists in consensus and no interobserver or intraobserver variability was assessed.

\section{CONCLUSION}

$A D C$ values obtained from DWI in endometrial cancers were differentiated between endometrioid and non-endometrioid 
carcinomas. In endometrioid carcinomas, high grade tumours had significantly lower ADC values compared to the low grade tumours. Important histopathological prognostic factors, namely, myometrial invasion depth, lymphovascular invasion, cervical involvement, lower uterine segment involvement, serosal involvement, and presence of lymph node metastasis, were not associated with ADC measurements.

\section{ETHICAL APPROVAL:}

The study was approved by the Institutional Ethics Committee.

\section{PATIENTS' CONSENT:}

As the study was a retrospective one, patients' consent was waived.

\section{CONFLICT OF INTEREST:}

The authors declared no conflict of interest.

\section{AUTHORS' CONTRIBUTION:}

MO: Conception and study design, literature review, data collection, image analysis, statistical analysis, results, writing the manuscript and critical review of the manuscript.

CK: Study design, data collection, image analysis, critical review of the manuscript.

MD: Data collection, image analysis, supervision.

MK: Data collection, histopathological analysis, supervision.

\section{REFERENCES}

1. Amant $F$, Moerman $P$, Neven $P$, Timmerman $D$, Van Limbergen E, Vergote I. Endometrial cancer. Lancet 2005; 366(9484):491-505. doi: 10.1016/S0140-6736(05)67063-8.

2. Tejerizo-García Á, Jiménez-López JS, Muñoz-González JL, Bartolomé-Sotillos S, Marqueta-Marqués L, López-González $G$, et al. Overall survival and disease-free survival in endometrial cancer: Prognostic factors in 276 patients. Onco Targets Ther 2013; 9:1305-13. doi: 10.2147/OTT.S51532.

3. Gadducci A, Cavazzana A, Cosio S, DI Cristofano C, Tana R, Fanucchi $A$, et al. Lymph-vascular space involvement and outer one-third myometrial invasion are strong predictors of distant haematogeneous failures in patients with stage III endometrioid-type endometrial cancer. Anticancer Res 2009; 29(5):1715-20.

4. Lee KB, Ki KD, Lee JM, Lee JK, Kim JW, Cho CH, et al. The risk of lymph node metastasis based on myometrial invasion and tumor grade in endometrioid uterine cancers: a multicenter, retrospective Korean study. Ann Surg Oncol 2009; 16(10):2882-7. doi: 10.1245/s10434-009-0535-0.

5. Tamai K, Koyama T, Saga T, Umeoka S, Mikami Y, Fujii S, et al. Diffusion-weighted MR imaging of uterine endometrial cancer. J Magn Reson Imaging 2007; 26(3):682-7. doi: 10.1002/ jmri.20997.

6. Harry VN, Deans H, Ramage E, Parkin DE, Gilbert FJ. Magnetic resonance imaging in gynecological Oncology. Int J Gynecol Cancer 2009; 19(2):186-93. doi: 10.1111/IGC. 0b013e31819c52de.

7. Manfredi R, Gui B, Giovanzana A, Marini S, Di Stefano M,
Zannoni G, et al. Localised cervical cancer (stage Radiol Med 2009; 114(6):960-75. doi: 10.1007/s11547-0090397-3.

8. Shen SH, Chiou YY, Wang JH, Yen MS, Lee RC, Lai CR, et al. Diffusion-weighted single-shot echo-planar imaging with parallel technique in assessment of endometrial cancer. AJR Am J Roentgenol 2008; 190(2):481-8. doi: 10.2214/AJR.07.2155.

9. Kilickesmez O, Bayramoglu S, Inci E, Cimilli T, Kayhan A. Quantitative diffusion-weighted magnetic resonance imaging of normal and diseased uterine zones. Acta Radiol 2009; 50(3):340-7. doi: 10.1080/02841850902735858.

10. Lin G, Ng KK, Chang CJ, Wang JJ, Ho KC, Yen TC, et al. Myometrial invasion in endometrial cancer: Diagnostic accuracy of diffusion-weighted 3.0-T MR imaging- initial experience. Radiol 2009; 250(3):784-92. doi: 10.1148/radiol.2503080874.

11. Rechichi G, Galimberti S, Signorelli M, Franzesi CT, Perego P, Valsecchi MG, et al. Endometrial cancer: correlation of apparent diffusion coefficient with tumor grade, depth of myometrial invasion, and presence of lymph node metastases. AJR Am J Roentgenol 2011; 197(1):256-62. doi: 10.2214/AJR.10.5584.

12. Cao K, Gao M, Sun YS, Li YL, Sun Y, Gao YN, et al. Apparent diffusion coefficient of diffusion weighted MRI in endometrial carcinoma-Relationship with local invasiveness. Eur J Radiol 2012; 81(8):1926-30. doi: 10.1016/j.ejrad.2011.04. 019.

13. Rechichi G, Galimberti S, Signorelli M, Perego P, Valsecchi MG, Sironi S. Myometrial invasion in endometrial cancer: Diagnostic performance of diffusion-weighted MR imaging at 1.5-T. Eur Radiol 2010; 20(3):754-62. doi: 10.1007/ s00330-009-1597-x.

14. Yan B, Zhao T, Liang X, Niu C, Ding C. Can the apparent diffusion coefficient differentiate the grade of endometrioid adenocarcinoma and the histological subtype of endometrial cancer? Acta Radiol 2018; 59(3):363-70. doi: 10.1177/0284185117716198.

15. Fujii S, Matsusue E, Kigawa J, Sato S, Kanasaki Y, Nakanishi J, et al. Diagnostic accuracy of the apparent diffusion coefficient in differentiating benign from malignant uterine endometrial cavity lesions: İnitial results. Eur Radiol 2008; 18(2):384-9. doi: 10.1007/s00330-007-0769-9.

16. Whittaker CS, Coady A, Culver L, Rustin G, Padwick M, Padhani AR. Diffusion-weighted MR imaging of female pelvic tumors: A pictorial review. Radiographics 2009; 29(3):759-74; discussion 774-8. doi: 10.1148/ rg.2930 85130.

17. Inoue C, Fujii S, Kaneda S, Fukunaga T, Kaminou T, Kigawa J, et al. Correlation of apparent diffusion coefficient value with prognostic parameters of endometrioid carcinoma. J Magn Reson Imaging 2015; 41(1):213-9. doi: 10.1002/jmri.24534.

18. Wang J, Yu T, Bai R, Sun H, Zhao X, Li Y. The value of the apparent diffusion coefficient in differentiating stage IA endometrial carcinoma from normal endometrium and benign diseases of the endometrium: Initial study at 3-T magnetic resonance scanner. J Comput Assist Tomogr 2010; 34(3):332-7. doi: 10.1097/RCT.0b013e3181d0f666.

19. Gallego JC, Porta A, Pardo MC, Fernández C. Evaluation of 
myometrial invasion in endometrial cancer: Comparison of diffusion-weighted magnetic resonance and intraoperative frozen sections. Abdom Imaging 2014; 39(5):1021-6. doi: 10.1007/s00261-014-0134-9.

20. Husby JA, Salvesen ØO, Magnussen IJ, Trovik J, Bjørge L, Salvesen HB, et al. Tumour apparent diffusion coefficient is associated with depth of myometrial invasion and is negatively correlated to tumour volume in endometrial carcinomas. Clin Radiol 2015; 70(5):487-94. doi: 10.1016/j.crad. 2014.12.016.

21. Yan B, Zhao T, Liang X, Niu C, Ding C. Can the apparent diffusion coefficient differentiate the grade of endometrioid adenocarcinoma and the histological subtype of endometrial cancer? Acta Radiol 2018; 59(3):363-70. doi: $10.1177 / 0284185117716198$.
22. Çavuşoğlu M, Sözmen Ciliz D, Ozsoy A, Duran S, Elverici E, Atalay CR, et al. Diffusion-weighted Mri of postmenopausal women with vaginal bleeding and endometrial thickening: Differentiation of benign and malignant lesions. J Belgian Soc Radiol 2016; 100(1):70. doi: 10.5334/jbr-btr.1118.

23. Bossuyt PM, Reitsma JB, Bruns DE, Gatsonis CA, Glasziou PP, Irwig L, et al. STARD 2015: An updated list of essential Items for reporting diagnostic accuracy studies. Radiology 2015; 277(3):826-32. doi: 10.1148/radiol.2015151516.

24. Hori M, Kim T, Onishi H, Imaoka I, Kagawa Y, Murakami T, et al. Endometrial cancer: Preoperative staging using three-dimensional T2-weighted turbo spin-echo and diffusion-weighted MR imaging at 3.0 T: A prospective comparative study. Eur Radiol 2013; 23(8): 2296-305. doi: 10.1007/s00330-013-2815-0. 